\title{
Caspase-3 Activation in Rat Frontal Cortex Following Treatment with Typical and Atypical Antipsychotics
}

\author{
L Fredrik Jarskog*, 1,2, John H Gilmore ${ }^{1,2}$, Leisa A Glantz ${ }^{1,2}$, Karissa L Gable', Thomas T German', \\ Ruth I Tong' and Jeffrey A Lieberman ${ }^{3}$ \\ 'Department of Psychiatry, University of North Carolina at Chapel Hill, Chapel Hill, NC, USA; ${ }^{2}$ Schizophrenia Research Center, University of \\ North Carolina at Chapel Hill, Chapel Hill, NC, USA; ${ }^{3}$ Department of Psychiatry, Columbia University, New York, NY, USA
}

\begin{abstract}
In schizophrenia, studies indicate that apoptotic susceptibility in cortex may be increased. A role for apoptosis in schizophrenia could potentially contribute to post-mortem evidence of reduced cortical neuropil and neuroimaging studies showing progressive cortical gray matter loss. Interestingly, antipsychotic treatment has been associated with higher cortical levels of anti-apoptotic Bcl-2 protein in rat cortex and preliminary data has suggested a similar association in schizophrenia and bipolar disorder. To better understand the effects of antipsychotics on apoptotic regulation, rats were administered haloperidol, clozapine, quetiapine, or saline daily for 4 weeks. Multiple apoptotic markers, including Bcl-2, pro-apoptotic Bax, anti-apoptotic XIAP, and the downstream protease caspase-3 were measured in frontal cortex using Western blot. Caspase-3 activity, activated caspase-3-positive cell number, and DNA/histone fragmentation levels were also determined. Western blot showed that immunoreactivity of $\mathrm{Bax}$ and $\mathrm{Bcl}-2$ bands were unchanged with treatment. However, mean density of the $19 \mathrm{kD}$ activated caspase-3 band was $55 \%$ higher with haloperidol $(p<0.00 \mathrm{I}), 40 \%$ higher with clozapine ( $p<0.05)$, and $48 \%$ higher with quetiapine $(p<0.0 \mathrm{I})$ compared to saline control. Specific activity of caspase-3 was also increased across all treatments $(p<0.0001)$, while DNA fragmentation rates remained unchanged. These data suggest that sub-chronic antipsychotic treatment is associated with non-lethal caspase-3 activity. The findings do not support a prominent Bcl-2-mediated neuroprotective role for antipsychotics. Although the association between antipsychotic treatment and increased pro-apoptotic caspase-3 is intriguing, further study is needed to understand its potential effects.
\end{abstract}

Neuropsychopharmacology (2007) 32, 95- 102. doi:I0.1038/sj.npp. I30 I074; published online 12 April 2006

Keywords: apoptosis; Bcl-2; clozapine; quetiapine; haloperidol; schizophrenia

\section{INTRODUCTION}

Although the pathophysiology of schizophrenia remains obscure, both neuroimaging and post-mortem studies have identified small reductions in cortical gray matter (Selemon and Goldman-Rakic, 1999; Shenton et al, 2001). Furthermore, longitudinal imaging studies of prodromal (Pantelis et al, 2003), childhood-onset (Sporn et al, 2003), and firstepisode psychosis (Cahn et al, 2002; Kasai et al, 2003) suggest that the reduction in cortical gray matter may be progressive, especially early in the course of illness.

Presented in part at the Society of Biological Psychiatry, 59th Annual Meeting, New York, NY, April 30, 2004; American College of Neuropsychopharmacology, 43rd Annual Meeting, San Juan, PR, December 14, 2004

*Correspondence: Dr LF Jarskog, Department of Psychiatry, University of North Carolina at Chapel Hill, 7025B Neuroscience Hospital, CB\# 7I60, Chapel Hill, NC 27599-7I60, USA, Tel: + I 9199668035 , Fax: + I 919966 8994, E-mail: jarskog@med.unc.edu

Received 17 August 2005; revised 17 February 2006; accepted 21 February 2006

Online publication: 7 March 2006 at http://www.acnp.org/citations/ Npp030706050520/default.pdf
Although several post-mortem studies have found no evidence of cortical neuronal loss (Pakkenberg, 1993; Selemon et al, 1995; Akbarian et al, 1995), other studies indicate layer-specific reductions of interneuron (Benes et al, 1991, 2001) and glial cell density (Cotter et al, 2002; Stark et al, 2004) in several cortical areas. Taken together, these data have led to the hypothesis that apoptosis could contribute to the loss of cortical volume in schizophrenia (Margolis et al, 1994; Jarskog et al, 2005). Supporting evidence include altered levels of apoptotic regulatory proteins in the Bcl-2 family in post-mortem temporal cortex (Jarskog et al, 2004) and altered DNA fragmentation patterns in anterior cingulate cortex (Benes et al, 2003). Although the impact of antipsychotic medications on these apoptotic changes has been uncertain, one post-mortem study found a preliminary association between prior exposure to antipsychotics and higher Bcl-2 levels in schizophrenia and bipolar disorder (Jarskog et al, 2000). Also, investigators found higher Bcl-2 protein and mRNA levels in rat cortex following 1 month of olanzapine and clozapine treatment (Bai et al, 2004).

Apoptosis involves interactions among several protein families that regulate activation of proteolytic caspases. 
Although multiple pathways can induce apoptosis, the mitochondrial pathway has most frequently been implicated in central nervous system (CNS) apoptosis (Yuan and Yankner, 2000). In this pathway, the prototypical and beststudied interaction occurs between pro-apoptotic Bax and anti-apoptotic Bcl-2 in the mitochondrial membrane, and their relative ratio is an important determinant of whether cytochrome $c$ is released in response to pro-apoptotic stimuli (Oltvai et al, 1993). If the Bax/Bcl-2 ratio is raised sufficiently, cytochrome $c$ is released by mitochondria and leads, through a series of steps, to activation of caspase-3, the principal effector caspase in the CNS (Yuan and Yankner, 2000). Before activation, caspase-3 must be released from inhibition by members of the inhibitor-ofapoptosis (IAP) protein family (Lotocki and Keane, 2002). Activation of caspase-3 is a well-recognized marker of apoptosis (Krajewska et al, 1997).

In order to better understand the potential relationship between antipsychotic treatment and apoptotic regulation, rats were treated with typical and atypical antipsychotics daily for 4 weeks and the effect on upstream and downstream apoptotic proteins by Western blot (Bax, Bcl-2, caspase -3 , and X-linked IAP (XIAP)), caspase-3 activity, caspase-3-immunopositive cell number, and DNA fragmentation in frontal cortex was measured. It was hypothesized that antipsychotic treatment would increase Bcl-2 immunoreactivity, reduce $\mathrm{Bax} / \mathrm{Bcl}-2$ ratio, and that clozapine and quetiapine would produce differentially greater effects than haloperidol on these measures. Furthermore, given the antiapoptotic effects of Bcl-2, it was expected that caspase-3 levels, activity, and cell number would not be altered from baseline.

\section{MATERIALS AND METHODS}

\section{Animals and Tissue Preparation}

This study was approved by the Institutional Animal Care and Use Committee of the University of North Carolina at Chapel Hill. Singly housed, male Sprague-Dawley rats (150$200 \mathrm{~g}$, Charles River) received daily i.p. injections of haloperidol $1 \mathrm{mg} / \mathrm{kg} /$ day $(n=12)$, clozapine $10 \mathrm{mg} / \mathrm{kg} /$ day $(n=13)$, quetiapine $10 \mathrm{mg} / \mathrm{kg} / \mathrm{day}(n=12)$, or saline $0.9 \%$ $(n=12)$ for 4 weeks. These doses are consistent with previous studies using in vivo rat models of neurochemical measures of cellular viability (Xu et al, 2002; Jarskog et al, 2004; Bai et al, 2004; Parikh et al, 2004; Fumagalli et al, 2004). One hour after the final dose, rats were killed and brains were removed and hemisected. Anterior right medial frontal cortex was dissected out and frozen on dry ice. Left hemicortex was frozen whole and $15 \mu \mathrm{m}$ coronal sections were cut using a cryostat (Bright Instruments, Huntingdon, UK) through the frontal cortex. All tissue was kept frozen at $-80^{\circ} \mathrm{C}$ until use.

\section{Homogenization}

Right medial cortex was placed in 10 volumes (w/v) of $50 \mathrm{mM}$ Tris- $\mathrm{HCl}$ buffer ( $\mathrm{pH} 7.4$ ) with $0.6 \mathrm{M} \mathrm{NaCl}, 0.2 \%$ Triton X-100, $0.5 \%$ BSA, $1 \mathrm{mM}$ benzamidine, $0.1 \mathrm{mM}$ benzethonium chloride, and $0.1 \mathrm{mM}$ PMSF. Samples were homogenized on ice for $30 \mathrm{~s}$ (PowerGen 125, Fisher
Scientific, Pittsburgh, PA) and sonicated for $10 \mathrm{~s}$ at $10 \mathrm{mV}$ (Sonic Dismembrator 60, Fisher Scientific). The homogenates were centrifuged for $15 \mathrm{~min}$ at $15000 \mathrm{~g}$ and at $4{ }^{\circ} \mathrm{C}$. Supernatants were assayed for total protein by the bicinchoninic acid method (Micro BCA Protein Assay Kit, Pierce Chemical, Rockford, IL). Chemicals were obtained from Sigma (St Louis).

\section{Semi-Quantitative Western Blots}

Samples were resolved on 8 (XIAP), 12 (Bcl-2, procaspase3), 14 (Bax), and 16\% (activated caspase-3) 10-well Trisglycine polyacrylamide mini-gels using established methods (Jarskog et al, 2000). Briefly, equal amounts of total protein $(10 \mu \mathrm{g}$ for Bax, $30 \mu \mathrm{g}$ for $\mathrm{Bcl}-2,20 \mu \mathrm{g}$ for procaspase-3, $100 \mu \mathrm{g}$ for activated caspase-3, $25 \mu \mathrm{g}$ for XIAP) were boiled for $5 \mathrm{~min}$ in Tris-glycine SDS sample buffer and applied to gels in triplicate. Two samples from each treatment arm, a low-range molecular weight ladder and a pooled sample were applied to each gel. Thus, for each protein, 18 gels were used to run each sample in triplicate. Band positions were verified with controls as follows: HeLa cell lysate for Bax and XIAP, Jurkat cell lysate for Bcl-2 and procaspase-3, and a recombinant human caspase-3 fragment for activated caspase- 3 that migrated to $17 \mathrm{kDa}$ (Pharmingen). Separated proteins were electrophoretically transferred to PVDF membranes (Immobilon-P, Millipore, Billerica, MA) at $25 \mathrm{~V}$ for $90 \mathrm{~min}$ and complete transfer was ascertained with Ponceau S stain. Membranes were blocked with 5\% (w/v) nonfat dry milk (Carnation brand) in $0.1 \%$ Tween in Tris-buffered saline (TBST) for $60 \mathrm{~min}$ at $25^{\circ} \mathrm{C}$ and then for $90 \mathrm{~min}$ at $25^{\circ} \mathrm{C}$ with primary antibodies as follows: monoclonal anti-human Bcl-2 (1:350, Pharmingen), polyclonal anti-rabbit Bax (N-20, 1:1500, Biotechnology, Santa Cruz, CA), polyclonal anti-rabbit procaspase-3 (H-277, $1: 200$, Santa Cruz), and monoclonal anti-human cleaved caspase-3 (IMG-144, 1:200, Imgenex); incubation with polyclonal anti-rabbit XIAP antibody ( $1: 1000$, Santa Cruz) was performed overnight at $4{ }^{\circ} \mathrm{C}$. Membranes were then washed and incubated for $90 \mathrm{~min}$ at $25^{\circ} \mathrm{C}$ with appropriate (anti-mouse or anti-rabbit) horseradish peroxidase-labeled secondary antibodies $(1: 3000$, Amersham Pharmacia, Piscataway, NJ), diluted in 5\% milk TBST. Membranes were developed using chemiluminescence (ECL, Amersham) and protein bands were detected on radiographic film (Hyperfilm ECL, Amersham). Optical densitometry was performed using the Bioquant system and image analysis using Adobe Photoshop 7.0. Band densities were normalized to the pooled sample that was applied to each gel to permit inter-gel comparisons. Finally, a standard curve of increasing protein amounts of pooled sample was immunoblotted for each protein to ascertain that all band densities fell within the linear portion of the densitometric curve. This linear relationship between increasing total protein levels and increasing immunodensity of the respective bands allows for comparisons of relative differences in protein quantity across samples.

\section{Caspase-3 Immunoprecipitation (IP)}

Homogenates within each treatment arm were equally pooled to produce one pooled sample per treatment arm. 
Samples were precleared for $30 \mathrm{~min}$ at $4{ }^{\circ} \mathrm{C}$ by addition of protein A-agarose beads (Santa Cruz). Samples were centrifuged and supernatants were transferred to new tubes, where monoclonal rabbit cleaved caspase-3 antibody ( $1: 100$, Asp 175, Cell Signaling, Beverly, MA) was mixed with $100 \mu \mathrm{g}$ of precleared protein and incubated for $24 \mathrm{~h}$ at $4{ }^{\circ} \mathrm{C}$ with agitation. Protein A-agarose was added and incubated with agitation for $2 \mathrm{~h}$ at $4^{\circ} \mathrm{C}$. Samples were centrifuged for $5 \mathrm{~min}$ at 2500 r.p.m. and at $4{ }^{\circ} \mathrm{C}$. The pellet was washed four times by centrifugation and resuspension in cold IP buffer $(50 \mathrm{mM}$ Tris pH7.5, $150 \mathrm{mM} \mathrm{NaCl}$, $0.1 \%$ Triton $\mathrm{X}-100$ ), and washed with $50 \mathrm{mM}$ Tris buffer $\mathrm{pH}$ 7.5. The bound cleaved caspase- 3 and its complexes were eluted from immunoaffinity beads by resuspension in $60 \mu \mathrm{l}$ Tris-glycine SDS sample buffer. Normal rabbit IgG antibody ( $1: 400$, Santa Cruz) diluted in sterile PBS was used for control IP. Samples were boiled for $5 \mathrm{~min}$ before immunoblotting for XIAP using methods as described above except that the primary XIAP antibody dilution was $1: 2000$.

\section{Caspase-3 Activity Assay}

Caspase-3-like activity was measured spectrophotometrically using the caspase- 3 colorimetric tetrapeptide substrate $\mathrm{N}$-acetyl-Asp-Glu-Val-Asp-p-nitroanilide (DEVD-pNa) in cortical homogenates using a 96-well microplate kit (Caspase-3 Cellular Activity Assay Kit, Calbiochem, San Diego, CA) according to the manufacturer's protocol. Briefly, $45 \mu \mathrm{l}$ of sample and $45 \mu \mathrm{l}$ assay buffer $(100 \mathrm{mM}$ $\mathrm{NaCl}, 50 \mathrm{mM}$ HEPES, $10 \mathrm{mM}$ DTT, $1 \mathrm{mM}$ EDTA, $10 \%$ glycerol, $0.1 \%$ CHAPS, pH7.4) were added to wells and the microplate was equilibrated at $37^{\circ} \mathrm{C}$. The reaction was initiated by adding $10 \mu \mathrm{l}$ of DEVD-pNA substrate $(200 \mu \mathrm{M}$ final concentration). Absorbance was recorded at $10 \mathrm{~min}$ intervals for $2 \mathrm{~h}$ at $405 \mathrm{~nm}$ using a microplate reader (Vmax, Molecular Devices, Sunnyvale, CA). All samples were run in duplicate and purified activated caspase- 3 was run on each microplate as a positive control. In this assay, the initial substrate concentration is saturating, leading to a linear absorbance $v s$ time relationship until the substrate begins to deplete, after which the absorbance gradually reaches a plateau. Specific activity of DEVD-pNa cleavage ( $\mathrm{pmol} \mathrm{pNa}$ / $\mathrm{min} / \mu \mathrm{g}$ total protein) for each sample was calculated by measuring the slope of the linear portion of the absorbance $v s$ time graph, as follows: specific activity=activity $\left(\operatorname{slope}\left(\Delta A_{\text {sample }} / \mathrm{min}\right) \times\left(50 \mu \mathrm{M} / A_{405(100 \mu \mathrm{l} \text { of } 50 \mu \mathrm{M} \mathrm{pNa}]}\right) \times 100 \mu \mathrm{l}\right.$ (assay volume) $) / \mu \mathrm{g}$ total protein.

\section{Activated Caspase-3 Immunohistochemistry}

Sections were fixed in cold $100 \%$ acetone for $10 \mathrm{~min}$, washed in PBS for $5 \mathrm{~min}$, then treated with $0.3 \%$ hydrogen peroxide in $100 \%$ methanol to remove endogenous peroxidases. Slides were hydrated through an ethanol gradient, then permeabilized and blocked in $5 \%$ goat serum in $0.3 \%$ Triton $\mathrm{X}-100$ (PBS-T) for $1 \mathrm{~h}$. Subsequently, slides were incubated for $24 \mathrm{~h}$ at $4{ }^{\circ} \mathrm{C}$ with rabbit polyclonal cleaved caspase-3 antibody $(1: 200$, Cell Signaling) in blocking solution, washed, and incubated for $1 \mathrm{~h}$ at $25^{\circ} \mathrm{C}$ with a secondary goat anti-rabbit biotinylated IgG antibody $(1: 200$, Vector Labs) in blocking solution. Sections were immunostained using the $\mathrm{ABC}$ method (Vectastain Elite Kit, Vector Labs, Burlingame, CA) and diaminobenzidine (DAB), counterstained with toluidine blue, dehydrated in an ethanol gradient, immersed in xylene and coverslipped. The specificity of the immunoreaction was assessed by performing all steps except leaving out the primary antibody in which case no immunolabeling was observed.

\section{Activated Caspase-3 Cell Counting}

Activated caspase-3 immunopositive cell density was assessed in left medial frontal cortex in the corresponding region of right medial frontal cortex that was homogenized for Western blotting. The starting point for cell counting was the anterior aspect of corpus callosum. Cells were counted within a $90^{\circ}$ sector formed by two perpendicular lines drawn from the superior tip of the corpus callosum, one drawn vertically to the superior cortical surface and one drawn horizontally to the medial cortical surface. Systematic random sampling of every 30th section among the first 100 sections was performed, starting with a randomly selected section among the first 10 sections that contained corpus callosum. Counting was performed blind to condition. Three sections were counted per brain using the StereoInvestigator system (MicroBrightField, Inc., Williston, VT) using a $250 \mu \mathrm{m}$ counting frame. Approximately, 300 caspase-3 immunopositive cells were counted per brain.

\section{Activated Caspase-3 Immunodensity}

Densitometric measurements of immunhistochemically stained cells in each section were quantified by capturing an image with a CCD camera connected to an Olympus microscope and a Bioquant Image Analysis system. For each section, a digital image was captured at $\times 2$ under the same illumination and camera settings, and a region of interest (ROI) was chosen at a fixed rectangular size (width: $500 \mu \mathrm{m}$; height: $2200 \mu \mathrm{m})$ placed within the same region used for cell counting adjacent to the corpus callosum. The measurement threshold used for each section was set at a level that excluded background and included only the dark pixels of the immunoreaction product, which indicated the varying levels of caspase-3 staining. Density was measured in relative grayscale units (0-255) with 0 being darkest and 255 lightest. Semi-automatic multiple average density measurements occurred in the ROI at $\times 20$ magnification on slightly overlapping fields of view to prevent redundancy, and generated numeric labels in order to keep a numeric count of stained cells.

\section{Cell Death Detection ELISA}

An ELISA assay kit for DNA/histone nucleosomes was used to quantify the rate of apoptosis across homogenized samples using the manufacturer's recommended methods (Cell Death Detection ELISA plus, Roche). This assay is analogous to measuring apoptosis-induced DNA laddering by Southern blot. The method is based on quantifying mono- and oligonucleosomes generated by apoptosis via endonuclease-mediated cleavage of chromatin into 180-base pair (bp) nucleosomes and multiples thereof. Nucleosomes 
are units of chromatin formed by a histone octamer wrapped by $146 \mathrm{bp}$ DNA. In this assay, $20 \mu \mathrm{l}$ homogenized samples $(80 \mu \mathrm{g}$ total protein/sample) were diluted with $80 \mu \mathrm{l}$ immunoreagent containing monoclonal mouse anti-histone (H1, H2A, H2B, H3, and H4) biotin and anti-DNA (single and double-stranded)-peroxidase antibodies and were placed in 96-well streptavidin-coated microplates. All samples were run in triplicate. A positive control using DNA-histone complex was run on each plate. Samples were shaken (300 r.p.m.) for $2 \mathrm{~h}$ at $25^{\circ} \mathrm{C}$ and unbound components were removed by rinsing with incubation buffer. A measure of $100 \mu \mathrm{l} \mathrm{ABTS} \mathrm{substrate} \mathrm{was} \mathrm{added} \mathrm{to} \mathrm{each} \mathrm{well,}$ the plate was incubated at $25^{\circ} \mathrm{C}$ while shaking (250 r.p.m.) and retained peroxidase was measured spectrophotometrically at $405 \mathrm{~nm}$ using a microplate reader (Vmax, Molecular Devices).

\section{Statistical Analysis}

Statistical analysis was performed using GraphPad Prism Version 4.01 (GraphPad Software, San Diego, CA). Outcome variables were compared by one-way analysis of variance (ANOVA) across all diagnostic groups with significance set at $p<0.05$. For significant changes by ANOVA, post hoc Dunnett's multiple comparison tests were also performed with two-tailed $p$-values considered significant at $p<0.05$.

\section{RESULTS}

\section{Bax and Bcl-2 Immunoblots}

Using semi-quantitative Western blots, immunoreactivity of Bcl-2 bands in rat frontal cortex did not show an effect of antipsychotic treatment by $\operatorname{ANOVA}(\mathrm{F}=0.69, \mathrm{df}=3,48$, $p=0.563$ ) (see Table 1). Although immunoreactivity of Bax bands showed a trend toward a medication effect $(\mathrm{F}=2.70$, $\mathrm{df}=3,48, p=0.057)$, post hoc analysis revealed no changes in Bax between the treatment arms (see Table 1). The Bax/ $\mathrm{Bcl}-2$ ratio has been identified as an important determinant of apoptotic vulnerability and neurons with high Bax/Bcl-2 ratio are more susceptible to undergo apoptosis (Oltvai et al, 1993; Vekrellis et al, 1997). The Bax/Bcl-2 ratio was derived by normalizing the optical density (OD) of Bax and Bcl-2 bands for each sample to the mean OD of the saline control group, respectively. Bax/Bcl-2 quotients of the normalized Bax and Bcl-2 values were calculated for each sample. This analysis did not show evidence of a medication effect on Bax/Bcl-2 ratios by ANOVA $(\mathrm{F}=0.994, \mathrm{df}=3,48$, $p=0.405)$ (see Table 1).

\section{Caspase-3 Immunoblots}

Immunoreactivity of procaspase-3 bands did not show an effect of antipsychotic treatment by ANOVA $(\mathrm{F}=0.32$, $\mathrm{df}=3,48, p=0.810$ ) (see Table 1 ). However, antipsychotic medications produced a robust effect on the immunoreactivity of the $19 \mathrm{kD}$ fragment of activated caspase- 3 by ANOVA $(\mathrm{F}=7.43, \mathrm{df}=3,48, p=0.0004)$ (see Figure 1). Activated caspase- 3 fragments are seen as multiple cleaved bands migrating in the $17-20 \mathrm{kD}$ range and a smaller band $\sim 12-14 \mathrm{kD}$ can sometimes be visualized (Faleiro et al, 1997). In the current study, a $19 \mathrm{kD}$ band was most abundant and clearly visualized across all samples while 17 and $20 \mathrm{kD}$ bands were very faint and no $12-14 \mathrm{kD}$ bands

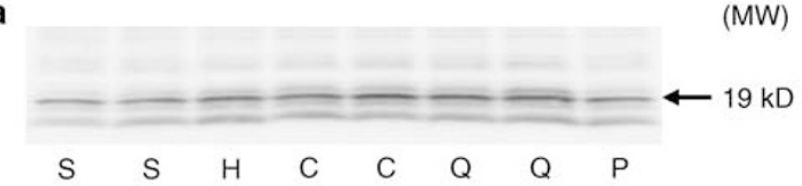

b

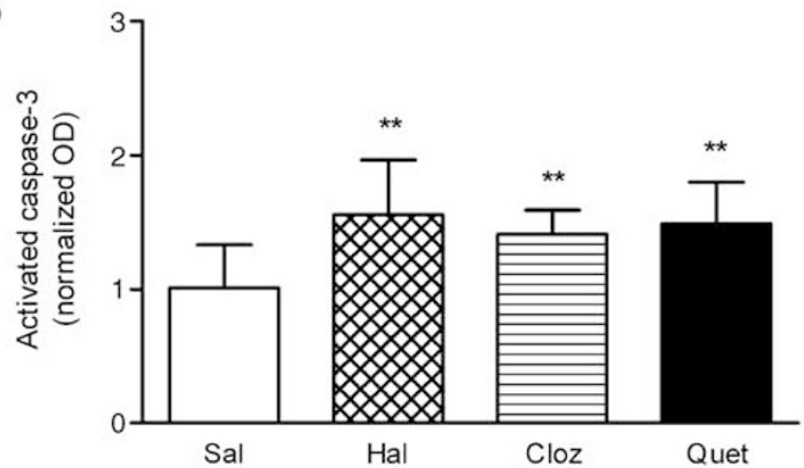

Figure I (a) Representative Western blot of activated caspase-3 in rat frontal cortex from animals treated daily for 4 weeks with i.p. saline (S) $0.9 \%$, haloperidol $(\mathrm{H}) 1 \mathrm{mg} / \mathrm{kg}$, clozapine (C) $10 \mathrm{mg} / \mathrm{kg}$, and quetiapine (Q) $10 \mathrm{mg} / \mathrm{kg}$. Pooled sample (P) was included to allow for inter-gel comparisons. Of the large fragments of activated caspase-3, only the $19 \mathrm{kD}$ molecular weight band was visualized in all samples. (b) A significant treatment effect emerged for activated caspase-3 levels by ANOVA. Compared to saline control, mean activated caspase-3 levels were 55\% higher with haloperidol (** $<<0.01), 40 \%$ higher with clozapine $(* * 0.01)$, and $47 \%$ higher with quetiapine $(* * p<0.01$ ) using post hoc Dunnett's multiple comparison tests.

Table I Immunoreactivity of Apoptotic Protein Bands by Semi-Quantitative Western Blot

\begin{tabular}{lccccrc}
\hline Treatment & Bax & Bcl-2 & Bax/Bcl-2 & Procaspase-3 & Act. caspase-3 & XIAP \\
\hline Saline & $1.41 \pm 0.27$ & $1.20 \pm 0.30$ & $1.06 \pm 0.34$ & $1.11 \pm 0.29$ & $1.01 \pm 0.32$ & $1.38 \pm 0.39$ \\
Haloperidol & $1.30 \pm 0.26$ & $1.10 \pm 0.20$ & $1.05 \pm 0.32$ & $1.10 \pm 0.24$ & $1.56 \pm 0.41 * *$ & $1.47 \pm 0.30$ \\
Clozapine & $1.53 \pm 0.25$ & $1.18 \pm 0.23$ & $1.13 \pm 0.28$ & $1.03 \pm 0.35$ & $1.41 \pm 0.18 * *$ & $1.40 \pm 0.29$ \\
Quetiapine & $1.25 \pm 0.27$ & $1.26 \pm 0.35$ & $0.91 \pm 0.35$ & $1.01 \pm 0.35$ & $1.49 \pm 0.31 * *$ & $1.33 \pm 0.34$ \\
\hline
\end{tabular}

Data represents normalized optical density measurements (mean $\pm \mathrm{SD}$ ) of immunoreactive bands representing Bax, Bcl-2, Bax/Bcl-2 ratio, procaspase-3, activated (act.) caspase-3 (19 kD fragment) and XIAP protein in rat frontal cortex following 4 weeks of daily treatment with haloperidol, clozapine, quetiapine, or saline.

*** $p<0.0$ l by post hoc Dunnett's multiple comparison test. 
were seen. Compared to saline control samples, the mean immunoreactivity of activated caspase- 3 (19kD fragment) bands were $55 \%$ higher with haloperidol $(p<0.01), 40 \%$ higher with clozapine $(p<0.01)$, and $47 \%$ higher with quetiapine $(p<0.01)$ using a post hoc Dunnett's multiple comparison test (see Table 1).

\section{XIAP Immunoblots}

Immunoreactivity of XIAP protein in frontal cortical homogenates showed no effect of antipsychotic treatment by ANOVA ( $\mathrm{F}=0.391, \mathrm{df}=3,47, p=0.760)$ (see Table 1 ). Similarly, there was no effect on XIAP bound to activated caspase-3 IP following treatment with haloperidol $(0.88 \pm 0.09)$, clozapine $(1.07 \pm 0.23)$, and quetiapine $(1.18 \pm 0.53)$ compared to saline $(1.0)$ by ANOVA $(\mathrm{F}=0.586, \mathrm{df}=3,11, p=0.641)$. Note that in the IP experiment, samples were pooled from each treatment arm and results were normalized to the saline control arm.

\section{Caspase-3 Activity}

Specific activity of DEVD-pNA cleavage (caspase-3-like activity) demonstrated a significant treatment effect $(\mathrm{F}=9.15, \mathrm{df}=3,47, p<0.0001)$ (see Figure 2). A post hoc Dunnett's test showed that specific activity of caspase- 3 was $30 \%$ higher in the haloperidol arm $(0.086 \pm 0.015$ pmol $\mathrm{pNa} / \mathrm{min} / \mu \mathrm{g}$ total protein, $p<0.01), 46 \%$ higher in the clozapine arm $(0.0970 \pm 0.020 \mathrm{pmol} \mathrm{pNa} / \mathrm{min} / \mu \mathrm{g}$ total protein, $p<0.01$ ), and $39 \%$ higher in the quetiapine arm $(0.093 \pm 0.014 \mathrm{pmol} \mathrm{pNa} / \mathrm{min} / \mu \mathrm{g}$ total protein, $p<0.01)$ when compared to the control arm $(0.066 \pm 0.012 \mathrm{pmol}$ $\mathrm{pNa} / \mathrm{min} / \mu \mathrm{g}$ total protein).

\section{Activated Caspase-3 Immunohistochemistry}

Activated caspase-3 immunopositive cells were found in all areas of medial frontal cortex in both saline and antipsychotic-treated animals (see Figure 3a). No effect emerged for activated caspase-3 cell density with haloperidol $(1.11 \pm 0.34$ normalized cell density), clozapine $(1.01 \pm 0.36)$ and quetiapine $(0.95 \pm 0.21)$ compared to saline $(1.00 \pm 0.21)$ by ANOVA $(\mathrm{F}=1.87, \mathrm{df}=3,140, p=0.138)$ (see Figure 3b). Similarly, there was no effect on activated caspase-3 immunodensity per cell with haloperidol $(35.75 \pm 15.50$ grayscale units), clozapine (33.04 \pm 10.98$)$, and quetiapine $(36.86 \pm 12.11)$ compared to saline $(33.79 \pm 10.02)$ by ANOVA $(\mathrm{F}=0.244, \mathrm{df}=3,48, p=0.865)$.

\section{DNA Fragmentation}

In this ELISA-based assay, histone-associated DNA fragment levels were measured. Apoptosis-induced histone/ DNA fragments are analogous to DNA laddering that is visualized with Southern blotting. Medial frontal cortex did not demonstrate an effect of antipsychotic treatment on histone-associated DNA fragmentation with haloperidol $(0.96 \pm 0.16$ absorption units (au)), clozapine $(0.97 \pm 0.13$ $\mathrm{au})$, and quetiapine $(1.06 \pm 0.14 \mathrm{au})$ compared to salinetreated animals $(1.06 \pm 0.13 \mathrm{au})$ by ANOVA $(\mathrm{F}=1.93, \mathrm{df}=3$, $48, p=0.139)$.

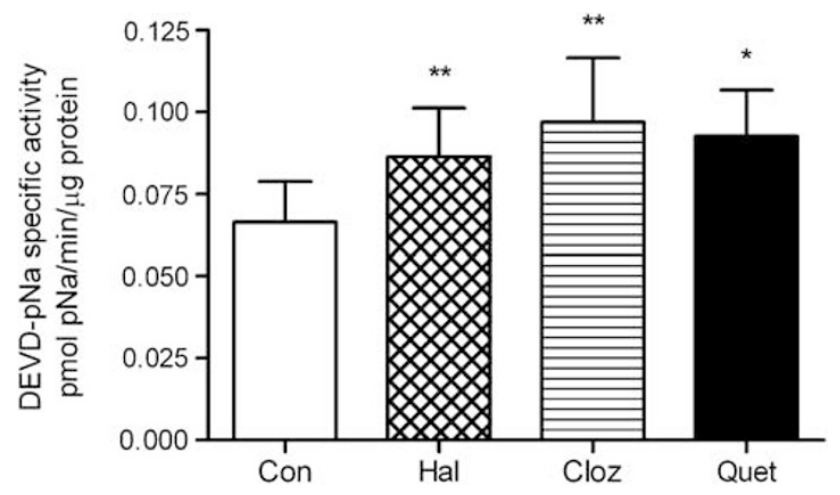

Figure 2 A significant effect of antipsychotic treatment was demonstrated on caspase-3-like activity measuring DEVD-pNA (Asp-Glu-Val-Aspp-nitroanilide) cleavage, by ANOVA $(F=9.15, d f=3,47, p<0.0001)$. Compared to control, post hoc Dunnett's multiple comparison tests showed caspase-3-like specific activity was $29.9 \%$ higher in the haloperidol arm (** $p<0.01$ ), $45.9 \%$ higher in the clozapine arm (** $p<0.01$ ), and $39.4 \%$ higher in the quetiapine arm $(* p<0.05)$.
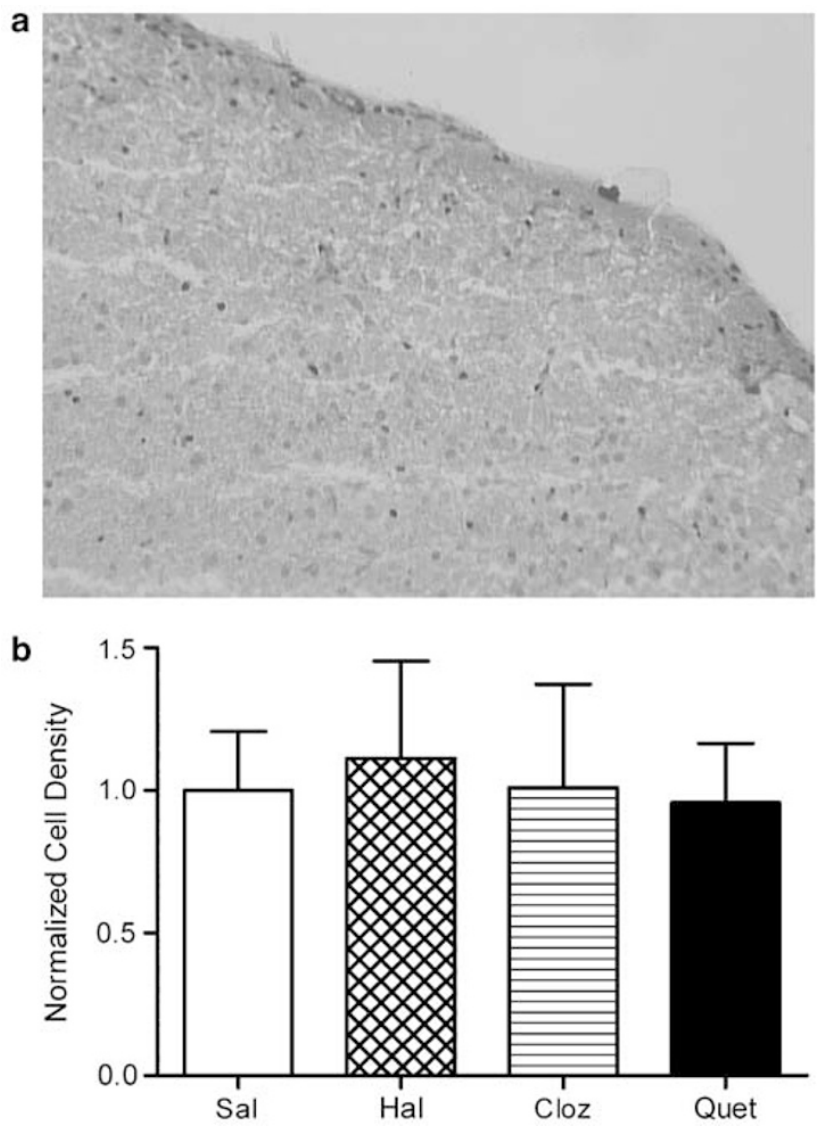

Figure 3 (a) Representative section of activated caspase- 3 immunohistochemistry at $\times 20$ following clozapine treatment. Caspase-3-positive cells are seen throughout the cortical layers. (b) Mean activated caspase-3immunopositive cell density was not altered between saline control, haloperidol, clozapine, and quetiapine treatment arms.

\section{DISCUSSION}

As Bcl-2 has been established as a potent neuroprotective (Oltvai et al, 1993; Zhong et al, 1993) and neurotrophic protein (Oh et al, 1996; Chen et al, 1997), the potential for 
antipsychotic-mediated Bcl-2 upregulation was examined. The particular interest in antipsychotic effects on Bcl-2 stemmed from the observation that $\mathrm{Bcl}-2$ was reduced in temporal cortex in schizophrenia, along with a preliminary association between higher cortical Bcl-2 levels in those patients previously treated with antipsychotics when compared with treatment-naive patients (Jarskog et al, 2000). Contrary to our hypothesis, immunodensity of Bcl-2 bands in rat cortex was not increased after 4 weeks of haloperidol, clozapine, or quetiapine treatment when compared to vehicle-control treated animals. Likewise, pro-apoptotic Bax immunodensity and Bax/Bcl-2 ratio were unchanged with antipsychotic treatment. This is in contrast to a study that found 4 weeks of clozapine and olanzapine treatment produced $30-50 \%$ higher $\mathrm{Bcl}-2$ mRNA and protein in rat frontal cortex and hippocampus (Bai et al, 2004). The main differences between these two studies were that a different rat strain was used by Bai et al (Wistar) as compared to the current study (Sprague-Dawley) and that only clozapine was used in common between the two studies. This could suggest strain-dependent differences in apoptotic signaling cascades or relate to pharmacokinetic differences. Based on the absence of an antipsychotic effect on Bcl-2 immunoreactivity in the current study, two main conclusions can be drawn. First, the current data do not support a prominent $\mathrm{Bcl}-2$-mediated neuroprotective effect of typical or atypical antipsychotics in frontal cortex. Second, these findings strengthen the conclusion that low Bcl-2 levels in schizophrenia relate to pathophysiology and do not represent a confounding effect of treatment.

Although $\mathrm{Bax}$ and $\mathrm{Bcl}-2$ were unchanged following treatment, typical, and atypical antipsychotic medications unexpectedly increased immunoreactivity and activity of activated caspase- 3 in rat cortex. Caspase proteins are cysteine-dependent proteases that serve to cleave specific structural and functional cellular substrates during apoptosis. Caspase-3 represents the predominant 'effector' caspase in the CNS, both in normal neurodevelopment and in neuropathological states (Yuan and Yankner, 2000). Western blotting demonstrated a $40-55 \%$ increase in immunoreactivity of activated caspase- 3 bands following 1 month of daily haloperidol, clozapine, or quetiapine treatment. Moreover, a previous study found that activated caspase-3 in rat cortex was not altered following 1 week of daily haloperidol treatment (Jarskog et al, 2004), suggesting that the increase in caspase- 3 is a delayed effect, occurring only after several weeks of treatment. Consistent with elevated immunoreactivity of activated caspase- 3 bands by Western blot, caspase-3-like specific activity was increased by $30-46 \%$ across the antipsychotic treatments. The current data represent the first in vivo evidence that both typical and atypical antipsychotics can activate caspase-3, a key downstream apoptotic protease that is extensively implicated in normal and pathological functions in the CNS.

To investigate the impact of increased caspase- 3 levels on cortical cell survival, relative levels of DNA fragmentation were assessed. DNA fragmentation is recognized as a hallmark of apoptotic activity (Arends et al, 1990), and occurs as a consequence of caspase-3-mediated cleavage of DNA fragmentation factor (DFF/CAD) and other key cellular substrates (Yuan et al, 2003). Owing to its association with DNA fragmentation, the presence of activated caspase- 3 has been identified as a marker for active apoptosis (Krajewska et al, 1997). However, in the current study, caspase-3 activation was not associated with increased rates of DNA fragmentation, indicating that antipsychotic treatment did not induce apoptosis. Taken together, these data indicate that sub-chronic antipsychotic treatment in a rat model is associated with non-lethal caspase- 3 activity.

Consistent with the DNA fragmentation data, activated caspase-3 immunopositive cell number in frontal cortex was unaffected by treatment. This suggested that higher activated caspase- 3 immunoreactivity may instead have increased on a per cell basis. By tracing caspase-3immunopositive cell bodies, immunoreactivity was numerically higher by $6 \%$ in the haloperidol group and $9 \%$ in the quetiapine group compared to saline control; however, this effect was not significant. Variability associated with immunohistochemical assessments could account for the failure to detect an increase in caspase-3 immunodensity per cell.

XIAP, a member of the IAPs, is a critical downstream inhibitor of apoptosis in the CNS that binds directly to active caspase-3 (Lotocki and Keane, 2002). As higher XIAP levels could potentially account for the absence of DNA fragmentation in the face of higher activated caspase-3 levels, XIAP levels were measured to rule out a potential effect of antipsychotics on XIAP. As demonstrated, total cortical XIAP levels did not differ between antipsychoticand saline-treated animals. Furthermore, XIAP bound to immunoprecipitated activated caspase- 3 was also unchanged across treatment groups. These data do not implicate XIAP in antipsychotic-mediated effects on caspase-3 activity.

The clinical relevance of increased caspase- 3 activity following 1 month of antipsychotic treatment remains uncertain. One possibility is that caspase- 3 activity could contribute to the evidence for progressive cortical gray matter loss in the early stages of schizophrenia (Gur et al, 1998; Cahn et al, 2002; Kasai et al, 2003; Lieberman et al, 2005). Yet, in human post-mortem studies, activated caspase-3 levels are slightly reduced in temporal cortex in schizophrenia (Jarskog et al, 2004), and the rate of neuronal DNA fragmentation is also reduced in anterior cingulate cortex in schizophrenia compared to control subjects (Benes et al, 2003). These differences in apoptotic marker profiles between schizophrenia cortex and the current antipsychotic-treated animal study suggest that the apoptotic deficits in schizophrenia are more likely to be pathophysiological in nature rather than an effect of treatment. Nevertheless, further study is needed to assess whether increased caspase-3 activity in response to antipsychotic treatment may be time-limited and whether such activity could impact synaptic viability, as has been suggested by evidence of caspase-3-mediated synaptically localized apoptotic activity (Mattson et al, 1998; Gylys et al, 2002).

A limitation of the current study is the uncertainty over the comparability and clinical relevance of the antipsychotic doses tested. The argument that antipsychotic dosing in rodent models often lacks relevance to the clinical condition is primarily based on studies of equivalent $\mathrm{D}_{2}$ receptor occupancy. One study found that clinically relevant $\mathrm{D}_{2}$ 
occupancy for single doses of quetiapine and clozapine are comparable to those used in the current study (Kapur et al, 2003), while for haloperidol, reports of comparable occupancy ranges from doses of $0.06 \mathrm{mg} / \mathrm{kg}$ (Kapur et al, 2003 ) to $0.6 \mathrm{mg} / \mathrm{kg}$ (Schotte et al, 1996). These studies suggest that our haloperidol dose was somewhat high. However, haloperidol plasma levels for long-term dosing at $1 \mathrm{mg} / \mathrm{kg} /$ day in rats is typically around $10 \mathrm{ng} / \mathrm{ml}$ (Gao et al, 1997; Andersson et al, 2002) and $10 \mathrm{ng} / \mathrm{ml}$ is also the plasma level that has associated with better clinical response in one of the few double-blind randomized studies that targeted specific haloperidol plasma levels - $2 \mathrm{ng} / \mathrm{ml}$ vs $10 \mathrm{ng} / \mathrm{ml}-$ in acutely ill schizophrenic patients (Volavka et al, 1995). By this measure, our haloperidol dose was not unreasonably high.

In conclusion, sub-chronic treatment with haloperidol, clozapine, and quetiapine was not associated with increased Bcl-2 immunoreactivity in rat frontal cortex. This finding does not support a Bcl-2-mediated neuroprotective effect of antipsychotics in frontal cortex. However, antipsychotic treatment was associated with increased levels and activity of caspase-3, a key downstream apoptotic protease that is extensively involved in CNS development and disease. The increase in caspase- 3 activity occurred without increased DNA fragmentation, indicating that this activity was probably non-lethal. Given several lines of evidence that apoptotic activity is downregulated in post-mortem cortex in the chronic stages of schizophrenia, this study indicates that the neuropathology of schizophrenia is not simply the result of the effects of antipsychotic medications on apoptotic signaling. Although speculative, it remains possible that caspase- 3 activity could contribute to the evidence for progressive neurostructural changes seen in the early stages of schizophrenia. Further studies are needed to understand the relationship between antipsychotic treatment and apoptotic regulation and the potential clinical impact of this interaction.

\section{ACKNOWLEDGEMENTS}

Research supported by grants from NIMH MH-01752 (LFJ) and the Investigator Sponsored Trial Program of AstraZeneca (LFJ).

\section{REFERENCES}

Akbarian S, Kim JJ, Potkin SG, Hagman JO, Tafazzoli A, Bunney Jr WE et al (1995). Gene expression for glutamic acid decarboxylase is reduced without loss of neurons in prefrontal cortex of schizophrenics. Arch Gen Psychiatry 52: 258-266.

Andersson C, Hamer RM, Lawler CP, Mailman RB, Lieberman JA (2002). Striatal volume changes in the rat following long-term administration of typical and atypical antipsychotic drugs. Neuropsychopharmacology 27: 143-151.

Arends MJ, Morris RG, Wyllie AH (1990). Apoptosis. The role of the endonuclease. Am J Pathol 136: 593-608.

Bai O, Zhang H, Li XM (2004). Antipsychotic drugs clozapine and olanzapine upregulate bcl-2 mRNA and protein in rat frontal cortex and hippocampus. Brain Res 1010: 81-86.

Benes FM, McSparren J, Bird ED, SanGiovanni JP, Vincent SL (1991). Deficits in small interneurons in prefrontal and cingulate cortices of schizophrenic and schizoaffective patients. Arch Gen Psychiatry 48: 996-1001.
Benes FM, Vincent SL, Todtenkopf M (2001). The density of pyramidal and nonpyramidal neurons in anterior cingulate cortex of schizophrenic and bipolar subjects. Biol Psychiatry 50: 395-406.

Benes FM, Walsh J, Bhattacharyya S, Sheth A, Berretta S (2003). DNA fragmentation decreased in schizophrenia but not bipolar disorder. Arch Gen Psychiatry 60: 359-364.

Cahn W, Pol HE, Lems EB, Van Haren NE, Schnack HG, van der Linden JA et al (2002). Brain volume changes in first-episode schizophrenia: a 1-year follow-up study. Arch Gen Psychiatry 59: 1002-1010.

Chen DF, Schneider GE, Martinou JC, Tonegawa S (1997). Bcl-2 promotes regeneration of severed axons in mammalian CNS. Nature 385: 434-439.

Cotter D, Mackay D, Chana G, Beasley C, Landau S, Everall IP (2002). Reduced neuronal size and glial cell density in area 9 of the dorsolateral prefrontal cortex in subjects with major depressive disorder. Cereb Cortex 12: 386-394.

Faleiro L, Kobayashi R, Fearnhead H, Lazebnik Y (1997). Multiple species of CPP32 and Mch2 are the major active caspases present in apoptotic cells. EMBO J 16: 2271-2281.

Fumagalli F, Molteni R, Bedogni F, Gennarelli M, Perez J, Racagni $\mathrm{G}$ et al (2004). Quetiapine regulates FGF-2 and BDNF expression in the hippocampus of animals treated with MK-801. Neuroreport 15: 2109-2112.

Gao XM, Hashimoto T, Cooper TB, Tamminga CA (1997). The dose-response characteristics of rat oral dyskinesias with chronic haloperidol or clozapine administration. J Neural Transm 104: 97-104.

Gur RE, Cowell P, Turetsky BI, Gallacher F, Cannon T, Bilker W et al (1998). A follow-up magnetic resonance imaging study of schizophrenia. Relationship of neuroanatomical changes to clinical and neurobehavioral measures. Arch Gen Psychiatry 55: $145-152$.

Gylys KH, Fein JA, Cole GM (2002). Caspase inhibition protects nerve terminals from in vitro degradation. Neurochem Res 27: 465-472.

Jarskog LF, Gilmore JH, Selinger ES, Lieberman JA (2000). Cortical bcl-2 protein expression and apoptotic regulation in schizophrenia. Biol Psychiatry 48: 641-650.

Jarskog LF, Glantz LA, Gilmore JH, Lieberman JA (2005). Apoptotic mechanisms in the pathophysiology of schizophrenia. Prog Neuropsychopharmacol Biol Psychiatry 29: 846-858.

Jarskog LF, Selinger ES, Lieberman JA, Gilmore JH (2004). Apoptotic proteins in the temporal cortex in schizophrenia: high $\mathrm{Bax} / \mathrm{Bcl}-2$ ratio without caspase-3 activation. Am J Psychiatry 161: 109-115.

Kapur S, VanderSpek SC, Brownlee BA, Nobrega JN (2003). Antipsychotic dosing in preclinical models is often unrepresentative of the clinical condition: a suggested solution based on in vivo occupancy. J Pharmacol Exp Ther 305: 625-631.

Kasai K, Shenton ME, Salisbury DF, Hirayasu Y, Lee CU, Ciszewski AA et al (2003). Progressive decrease of left superior temporal gyrus gray matter volume in patients with first-episode schizophrenia. Am J Psychiatry 160: 156-164.

Krajewska M, Wang HG, Krajewski S, Zapata JM, Shabaik A, Gascoyne $\mathrm{R}$ et al (1997). Immunohistochemical analysis of in vivo patterns of expression of CPP32 (Caspase-3), a cell death protease. Cancer Res 57: 1605-1613.

Lieberman JA, Tollefson GD, Charles C, Zipursky R, Sharma T, Kahn RS et al (2005). Antipsychotic drug effects on brain morphology in first-episode psychosis. Arch Gen Psychiatry 62: 361-370.

Lotocki G, Keane RW (2002). Inhibitors of apoptosis proteins in injury and disease. IUBMB Life 54: 231-240.

Margolis RL, Chuang DM, Post RM (1994). Programmed cell death: implications for neuropsychiatric disorders. Biol Psychiatry 35: 946-956. 
Mattson MP, Keller JN, Begley JG (1998). Evidence for synaptic apoptosis. Exp Neurol 153: 35-48.

Oh YJ, Swarzenski BC, O’Malley KL (1996). Overexpression of Bcl2 in a murine dopaminergic neuronal cell line leads to neurite outgrowth. Neurosci Lett 202: 161-164.

Oltvai ZN, Milliman CL, Korsmeyer SJ (1993). Bcl-2 heterodimerizes in vivo with a conserved homolog, Bax, that accelerates programmed cell death. Cell 74: 609-619.

Pakkenberg B (1993). Total nerve cell number in neocortex in chronic schizophrenics and controls estimated using optical disectors. Biol Psychiatry 34: 768-772.

Pantelis C, Velakoulis D, McGorry PD, Wood SJ, Suckling J, Phillips LJ et al (2003). Neuroanatomical abnormalities before and after onset of psychosis: a cross-sectional and longitudinal MRI comparison. Lancet 361: 281-288.

Parikh V, Khan MM, Mahadik SP (2004). Olanzapine counteracts reduction of brain-derived neurotrophic factor and TrkB receptors in rat hippocampus produced by haloperidol. Neurosci Lett 356: 135-139.

Schotte A, Janssen PF, Gommeren W, Luyten WH, Van GP, Lesage AS et al (1996). Risperidone compared with new and reference antipsychotic drugs: in vitro and in vivo receptor binding. Psychopharmacology (Berlin) 124: 57-73.

Selemon LD, Goldman-Rakic PS (1999). The reduced neuropil hypothesis: a circuit based model of schizophrenia. Biol Psychiatry 45: 17-25.

Selemon LD, Rajkowska G, Goldman-Rakic PS (1995). Abnormally high neuronal density in the schizophrenic cortex. A morphometric analysis of prefrontal area 9 and occipital area 17. Arch Gen Psychiatry 52: $805-818$.
Shenton ME, Dickey CC, Frumin M, McCarley RW (2001). A review of MRI findings in schizophrenia. Schizophr Res 49: $1-52$.

Sporn AL, Greenstein DK, Gogtay N, Jeffries NO, Lenane M, Gochman P et al (2003). Progressive brain volume loss during adolescence in childhood-onset schizophrenia. Am J Psychiatry 160: 2181-2189.

Stark AK, Uylings HB, Sanz-Arigita E, Pakkenberg B (2004). Glial cell loss in the anterior cingulate cortex, a subregion of the prefrontal cortex, in subjects with schizophrenia. Am J Psychiatry 161: 882-888.

Vekrellis K, McCarthy MJ, Watson A, Whitfield J, Rubin LL, Ham J (1997). Bax promotes neuronal cell death and is downregulated during the development of the nervous system. Development 124: $1239-1249$.

Volavka J, Cooper TB, Czobor P, Meisner M (1995). Plasma haloperidol levels and clinical effects in schizophrenia and schizoaffective disorder. Arch Gen Psychiatry 52: 837-845.

Xu H, Qing H, Lu W, Keegan D, Richardson JS, Chlan-Fourney J et al (2002). Quetiapine attenuates the immobilization stressinduced decrease of brain-derived neurotrophic factor expression in rat hippocampus. Neurosci Lett 321: 65-68.

Yuan J, Lipinski M, Degterev A (2003). Diversity in the mechanisms of neuronal cell death. Neuron 40: 401-413.

Yuan J, Yankner BA (2000). Apoptosis in the nervous system. Nature 407: 802-809.

Zhong LT, Sarafian T, Kane DJ, Charles AC, Mah SP, Edwards RH et al (1993). Bcl-2 inhibits death of central neural cells induced by multiple agents. Proc Natl Acad Sci USA 90: 4533-4537. 